\title{
Customer Value Controlling - Combining Different Value Perspectives
}

\author{
Andreas Krämer ${ }^{1,2}$, Thomas Burgartz ${ }^{1}$ \\ ${ }^{1}$ BiTS, Business and Information Technology School, Iserlohn, Germany \\ ${ }^{2}$ exeo Strategic Consulting AG, Bonn, Germany \\ Correspondence: Andreas Krämer, exeo Strategic Consulting AG, Wittelsbachhering 24, 53115 Bonn, Germany
}

\author{
Received: April 23, 2015 Accepted: April 29, 2015 Online Published: May 10, 2015 \\ doi:10.11114/bms.v1i2.814 \\ URL: http://dx.doi.org/10.11114/bms.v1i2.814
}

\begin{abstract}
The article begins by presenting a model for the structuring of customer data which can be used to demonstrate the value of data in different forms of aggregation. Since Customer Value plays a crucial role in this model the term is examined more closely. As part of a value-based customer relationship management critical parameters are customer benefits and customer profitability. Both perspectives are included in the term Customer Value. A segmentation approach is shown which integrates the key measures of customer relationship management: value generation from the customer perspective ("Value to the Customer") and value generation from the company's perspective ("Value of the Customer"). The practical application of the method is demonstrated with typical cases concerning both, B2B as well as B2C markets.
\end{abstract}

Keywords: customer orientation, decision making, three-layer model, value to the customer, value of the customer, value-to-value-segmentation

\section{Introduction}

The increased use of the internet (social media), the digitization of the economy and the use of loyalty programs are just a few drivers that lead to a sudden increase of the available customer data. These data must be qualified and evaluated if they are to be used for decision-making within the company. It is a challenge to structure the available data and compress to Root. The cost of data management is only worthwhile if the information leads to new insights regarding their own customers and ultimately to value-added activities, thus increasing the company's profitability.

The term customer value is often used in the literature, this, however, has different meanings. Woodruff's (1997) definition of customer value is widely cited and encompasses most interpretations of customer value. Woodruff defines customer value as: "a customer perceived preference for and evaluation of those products attributes, attribute performances, and consequences arising from use that facilitate (or block) achieving the customer's goals and purposes in use situations". To date, an exact definition of customer value has been elusive to researchers. The ambiguity of customer value is well reflected in various definitions given by researchers. (Zeithaml,1988) provides one of the most widely cited definitions of customer value as "the consumer's overall assessment of the utility of a product based on perceptions of what is received and what is given" (p. 14).

Other authors rather focus on the profitability of individual customers and state that "many firms today quantify the value of individual customers and serve them differentially; providing better privileges, discounts or other inducements to high value customers" (Subramanian, Raju and Zhang, 2007).

The aim of this paper is firstly to develop a model for the structuring of customer data, secondly, to examine the concept of Customer Value in two perspectives ("Value to the customer" and "Value of the Customer") and thirdly to present an approach to combine both value perspectives and thus create a basis for value-oriented corporate management.

\section{Customer Relationship: Three-layer Model}

The customers' growing market power is on the one hand due to an increasing competition and increasing maturity in numerous product markets, on the other hand, due to the far-reaching possibilities of modern information technology and the globalization of product availability. As a consequence, the successful customer relationship occurs as an equal parameter besides product features and success. The customer, however, not only constitutes a purchasers and user of the product or performance. Moreover, he is the recipient of experiential knowledge, ideas and innovation. The efficient use of this customer-related information is an important approach to the creation of customer satisfaction while 
providing a workspace of a customer-oriented management and controlling (Burgartz, 2008). Efficient utilization of customer-related information can significantly improve the company-customer relationship. The implementation of an efficient and computerized information system is becoming more urgent due to the ever-growing quantity of information needed for processing, as well as the many different types of data sources, such as sales data, CRM, social media, market research data and big data. Internal and external data of the company is made available with the use of an appropriate information system, which is used by corporate management at the right time and at the right place. Information systems can also be used in a strategic manner to gain advantages over competitors.

To capture and manage customer relationships holistically, a customized analysis is required. In this context, we developed a three-layer model, which can be used to detail and structure the existing customer relationship:

\subsection{Exterior Layer: Business Model (Business Strategy)}

In this layer, the dimensions technology, competition, positioning and financial and corporate planning will be considered:

Technology: Technological advancements have allowed the networking of data to be further optimized and more cost-effective. This leads to extensive investments in Customer Relationship Management (CRM) systems. Global expenses for CRM systems are expected to rise from US \$13.9 billion in 2010 to US \$37 billion in 2017. This represents an average increase of more than $15 \%$ p.a. Companies that established online sales activities early, benefit from the profits due to a differentiated sales strategy. In 2012, approximately 2.5 Exabyte of data were generated each day and this figure doubles every 40 months. This accounts for more than the cumulated data volume of the whole Internet over the past 20 years.

Competition: International companies are not only subject to fierce global competition but must also meet many regionally different market requirements. A special challenge for those companies is to keep track of market trends and at the same time adapt to changing customer demands. This is especially applicable to medium-sized companies. In 2012, Germany had more than 1,300 medium-sized companies with a leading position in its core markets (hidden champions) - four times more than the US and six times more than Japan (Der Spiegel, 2013). However, the perceived intensity of competition even intensifies: Studies show that the proportion of companies with global operations, who see themselves in a price war, has increased from 46\% (2011) to 59\% in 2012 (SKP 2013).

Positioning: Still, the creation and defense of strategic competitive advantage is a core task of business management. However, both technological change and changing competitive conditions are such that the positioning can change quickly. In this context, the innovation management plays a special role. According to a recent study $83 \%$ of companies regard innovations already as important or essential to survive in the global competition. The group of innovative companies (top 20 percent) is, on average, almost $16 \%$ faster in growth during the past three years, than the group of firms has been classified the least innovative ( $\mathrm{PwC}, 2013)$.

Finance strategy and management of resources: Ever since the global financial crisis, awareness of the interdependencies and complexity in international markets has risen sharply. The controlling activities within a company face the challenge to involve greater volatility of markets and thus higher uncertainty in the planning processes. Meanwhile, this is subsumed by the term VUCA (Volatility, Uncertainty, Complexity, Ambiguity).

These changes include both opportunities and risks: On the one hand entrepreneurial activity is complicated by the increased complexity, on the other hand this leads to an increased need for networked data that provide a real-time overview of the company's situation and demonstrate a clear need for action. One consequence is that the investments will increase in the development of management information systems during the coming years. At the same time the changes described above provide a framework for customer relationship controlling. These form the outer layer of the model in figure 1, which helps to understand and influence the relationship between companies and their customers:
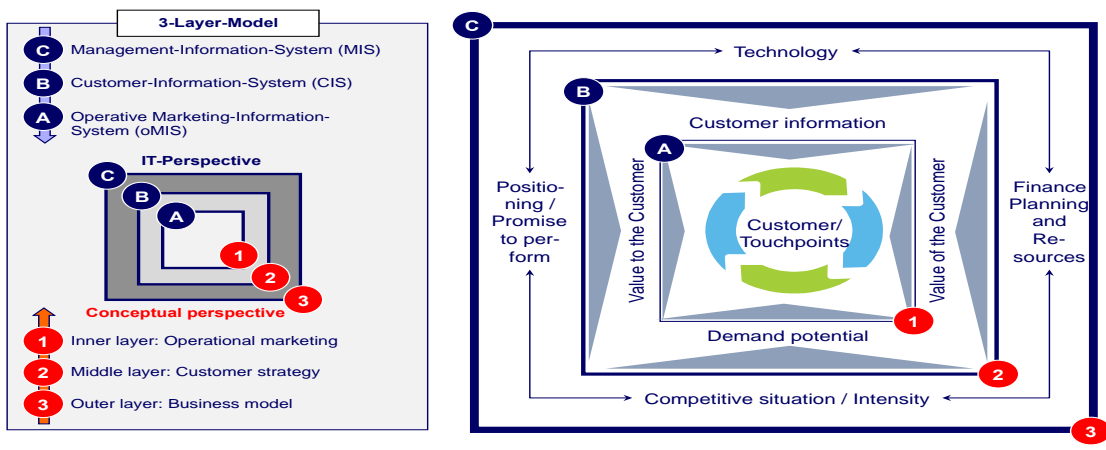

Figure 1. Customer Relationship and the Three-layer Model 


\subsection{Middle Layer: Customer Strategy (Information- and Value-Strategy)}

The revealed changes regarding the business model of companies, which was shown in the first layer, have consequences for the customer relationship strategy. In this middle layer customer information, value to the customer, value of the customer and demand potential are discussed.

Customer information: The starting point for operational control of the market development is a comprehensive and detailed understanding of customers. In addition, to improve customer loyalty typical reward programs have the "side effect" that the operators of loyalty programs receive detailed information on the revenues incurred by the customer transactions. Offering loyalty programs provides the opportunity to analyze the development of various customer segments.

Customer benefits (Value to the customer): Gaining customer benefits companies have to focus marketing activities in order to achieve optimal customer orientation. Besides the pure product benefit, many corporations are investing in strengthening the relationship benefit through additional customer service and customer retention operations in form of customer clubs and loyalty programs.

Customer value (Value of the customer): In addition to the process of benefit- and value generation for the costumer ("value creation"), it is very important, that the investments in the customer benefits can be recapitalized in form of an increasing company value ("value appropriation"). The calculation of the customer value is very demanding, if it goes beyond the perspective of simple ABC (revenue) segmentations.

Demand potential (Share-of-wallet): To ensure a comprehensive appraisal of the customer's potential increased buying will additionally be included in the realizable customized marginal incomes which result from the rising steady purchase and the intensity of the purchase in the original product assortment, as well as additional purchases in new complementary product categories. In addition to monetary value propositions - that have been considered until now and that arise from operations with the consumers themselves - indirect contributions should also be respected in growth potentials, which arises from interactions between customers and other consumers which lead to recruitment of new customers by recommendations (Cornelsen, 2000).

In general, it is less crucial, whether the corporate management should admit a higher significance to the perspective of customer value or customer benefit. Both value perspectives need to be connected, since a pure focus on customer benefits includes the risk of profit potentials not being exhausted (for example when the willingness to pay is underestimated, product prices are set at a lower level than reasonable and therefore a consumer surplus is generated). On the other side, an excessive focus on the financial parameters includes the risk that the market developments based on changed customer needs are missed.

\subsection{Interior Layer: Operative Marketing (Customer / Touch Points)}

The requirements, which were created by the data preparation in the two exterior layers, lead to an increase in efficiency in the operative marketing. First, processes are required, which allow a profitability oriented controlling of the marketand the customer handling measures (Return on Marketing). For a decision-oriented structure of the Marketing-Information-System (MIS) a sufficient data volume, a holistic market view and comparable, as well as standardized methods for evaluation are required. Moreover, it is necessary to analyse the efficiency of the customer-related processes (investments in communication, service improvement, product variations) and the relevance of several submarkets and customer segments (operative Marketing-Information-Systems).

\section{IT-supported Customer Value}

In order to establish a successful customer relationship controlling the terms customer benefit and customer value play a crucial role. Those dimensions become measurable and evaluable, once useful and valid customer information are provided as core parameters.

\subsection{Customer Information and Its Transformation into IT-Systems}

The awareness about the relevance of information as competition factor is constantly growing and thereby the understanding, that the achievements and the ability to generate further value within a corporation are significantly depending on the quality of the information supply of the operational units. Customer-oriented information systems (CIS), like Database Marketing, Computer Aided Selling and Online Marketing, for the purpose of a decision-oriented customer relationship controlling, need to ensure an intensified coordination and cooperation between the areas of functioning marketing-, sales-, and customer relationship-controlling and thereby all in the company available customer data. If relevant basis data is available beyond customer information marketing (sector, size of the company, socio-demographic data and risk data), acquisition efforts can be arranged more efficiently. Technological progress allows companies to gain high transparency of purchase and insights into the behavior of different customer segments. 
This applies to the online and offline channels. Once credit cards or customer loyalty cards are used during a purchase process, a dynamic data flow is initiated. While the generation of customer data is not a severe problem anymore, there is a growing challenge for a meaningful utilization and interpretation of customer information. The most successful business models of the last decade - Amazon, eBay, Google and Facebook - have followed this approach and developed complex systems for customer data analysis (Murray, 2013). Today, these instruments - together with an extraordinarily high degree of customer satisfaction - represent a key strategic competitive advantage of these firms (Gordon, 2013).

\subsection{Operationalization of the Customer Benefit (Value to the Customer)}

Customer value (Value to the customer) is defined as net benefits - the difference between the positive benefit components of a service or product, as a measure of the satisfaction of needs of a customer - and his disutility components in the form of the cost of acquisition and utilization of the service (price, time etc.). When making a purchase decision customers have the option to choose the alternative with the best value, for example the one with the best cost-benefit difference (Menon et al. 2005). The ability to measure the customer's key requirements is therefore essential for the successful development of the first sub-process of a customer relationship controlling (value creation). In order to support decisions concerning operational marketing activities customer segments have to be defined, in case that no real 1:1 marketing is applied (see figure 2).

If it is possible to measure the preference structure of individual customers, suppliers would have a full view of the customers' behavior and transactions. In this case, for example, for online dealers, conclusions from the actual behavior of customers can be drawn to build a picture of the customers' preferences and the drivers of the customers' decisions. In case no or only fragmented information about the customers and their transactions are on hand, this becomes more difficult. Then it is possible and suitable to use empirical studies to overcome data gaps. Today, a set of different methods exists to measure customers' benefits: Direct methods focus on the assessment of relevant product features and their importance. To ensure a trade-off while simulating the purchase decision, other tools like conjoint measurement can be used. Regardless of the method, it is crucial in a first step to separate benefit and cost components into individual blocks (fig. 2 left side).
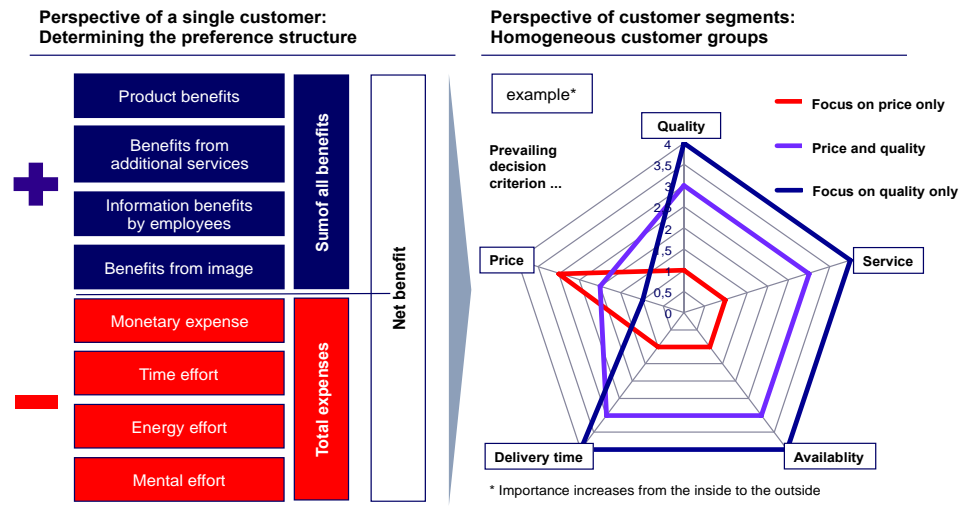

Figure 2. Customer net benefit and segmentation based on needs

During a second step it should be attempted to identify the drivers of net benefits (Fig. 2 right side) and to cluster single customers at the level of customer groups. The allocation of marketing resources on activities to meet customer needs is an important process to create a sustainable competitive advantage. In order to edit the second process of capitalization of customer value in the market, the value of the customer has to be measured.

\subsection{Operationalization of the Customer Value (Value of the Customer)}

The successful creation of the second sub-process (benefit capitalization) requires the measurement of the customers' value. In our understanding customer value is a monetary, profit-oriented dimension. That implies, that it includes an evaluation of the revenues and the customer specific costs of a business relationship in the customer life circle (Reinartz Krafft, 2001). In general, the customer value is conceptualized by two dimensions:

Base value

Growth value (up selling-, cross selling and reference potential).

At this point the first task is to determine the period to calculate the base value. The base value is usually operationalized through the contribution margin of the customer from the last reporting period, ${ }^{1}$, which can easily be

\footnotetext{
${ }^{1}$ Depending on your perspective and analyzed industry, a longer forecast period can be selected. Thus, the observation of a CLV-20-year period, for example in the automotive industry is not uncommon (Gordon, 2013).
} 
provided by the accounting department. According to numerous empirical findings, the contribution margin from the last reporting period is a very good predictor of future gross margin and thus the potential value that can be expected relatively safe (Venkatesan and Kumar, 2004). However, this is not universally valid knowledge. Depending on the business model and the buying cycles in the market, it could be useful to consider a period of more than five years for the customer value. Regarding the growth value it is suitable to differentiate between up-selling, cross-selling and indirect revenue effects due to references and recommendations. Driven by technological progress within the internet and social media, product reviews and recommendations are enjoying a growing importance.

\section{Integration of the Dimensions „Value to the Customer“ and „Value of the Customer“}

\subsection{Conceptional Approach}

Studies show that although companies provide similar services to clients the degree of financial success varies significantly (Slotegraaf et al., 2003; Pan and Luo, 2006). Apparently, companies differ in the second fundamental process of creating competitive advantages, which reflects the profitable exploitation of the benefits generated on the market. One explanation could be that the relationship between customers' benefit and customer value varies strongly across customer segments and companies differ in the ability and willingness to align service offerings targeted to the benefit requirements of the valuable customer segments or to prioritize these segments.

In an exchange relationship, realizable value creation can be increased through cooperative behavior of customers and suppliers. Therefore, a feedback of the two constructs is quite plausible and theoretically justified (Cornelsen, 2000). However, situations are conceivable in which the customer, due to switching-barriers or individual inertia, builds and maintains a business relationship with the vendor even though the calculated customer value is slightly positive or negative. Therefore, an assessment of the customer-and market-specific conditions by the supplier is crucial.

It is understandable that both perspectives are legitimate (see figure 3): Besides the process of value creation for the customer, it is important to enhance the overall perspective and include the financial view and answer the question how customer value can be transformed into company value.

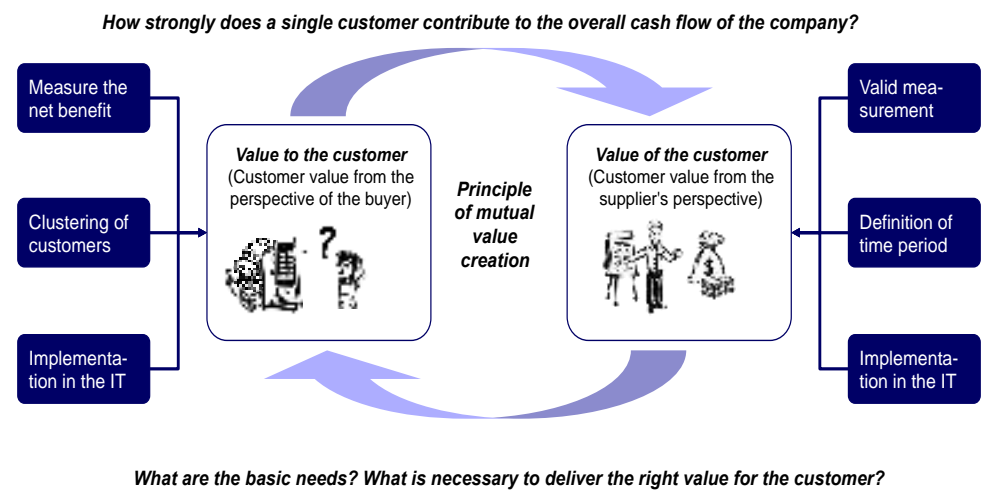

Figure 3. Link between, Value to the customer"and „Value of the customer"

Because of increasing marketing- and distribution expenses at coevally diminishing budgets the challenge is to concentrate on both processes - effective creation of benefits and value capitalization. Companies offering products and services with extraordinarily high perceived value, possibly will be surpassed by companies that offer a lower level of utility, but at the same time have a higher ability to capitalize value to the customer into a high customer value. Therefore, companies are well advised not to focus on a product with maximized customer benefits, which therefore promises a high market share (Krämer et al., 2003). This can be explained with a simple example: Suppose a company reduces the effective price level area-wide in the market, then two consequences result from this. First, the net benefit from a customer perspective is increased while the product quality level is unchanged. The "Value to the Customer" (economically the "consumer surplus") has obviously been increased. ${ }^{2}$ Secondly, it is not clear yet whether the price reduction will lead to a higher customer value. This depends on how elastic the market reacts to the price reduction. In case that the demand reaction is inelastic, the final outcome will be a reduction of the accumulated customer value.

The relationship between customer benefits and customer value has been only partially studied empirically. Rust et al.

\footnotetext{
2 An illustrative example is the launch of the Apple II in 1977. While Steve Wozniak was aiming to cover the cost of materials with the sales price and therefore proposed a rather low price level, Steve Jobs had a clear profit target. The retail price was set to $\$ 666$, about three times more than the production costs (Isaacson, 2011).
} 
(2004) examine the question to what extent improvements in quality lead to an increase of the customer lifetime value (CLV). For airlines, their analysis shows that a benefit increase of 0.2 index points generates a CLV increase of $1.39 \%$ on average over the 355 interviewed subjects. Similarly, Pan / Luo (2006) analyze the relationship between perceived service value and the altitude of the price premium achieved and the size of the customer base. They show that a significant part of the service investments is not reflected by a corresponding price premium. However, both studies consider only an average relation for the total sample of customers of a business or a variety of companies in various industries. Thus, these studies assume certain homogeneity across customers and businesses with regard to the transformation of customer value in customer value, which is unlikely to occur (Hahn et al., 2002). Supposing that different benefit segments exist, customer value would significant differ similarly.

The company's success will greatly depend on the allocation of marketing resources on the market segments with high customer value. Considering the heterogeneity it is necessary to segment customers the two value perspectives are included. This procedure is presented as "value-to-value approach" in the following.

\subsection{Methodology}

The challenge of merging the two value perspectives is on the one hand to provide information concerning the perception and the benefits from product characteristics or preferences of the customers for each customer. On the other hand, parameters for the calculation of the customer value (profitability) have to be determined. Diverse tools are available for both aspects: (1) value drivers for the customer can be generated for example by surveys (preference research can be due to direct methods like using scales and indirect methods like conjoint measurement). However, In addition there are also ways by tracking customer behavior to determine customer preferences, for example, through the monitoring of the behavior or tracking online activities. Furthermore, observing the buying decision and purchase history of the customers may also be helpful to understand whether an individual customer behaves consistently price sensitive or not (figure 4).

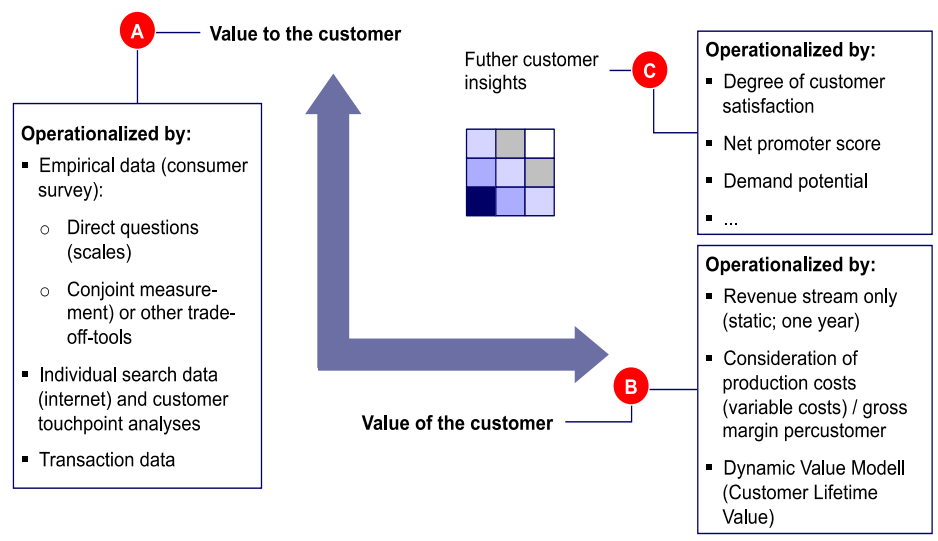

Figure 4. Methodology to combine „Value to the customer" and „Value of the customer"

With regard to customer profitability from the company's perspective, there are different ways to calculate: In a simple case there is a focus only on the revenue stream of an individual customer, without further consideration of the costs. This can be useful if the marginal costs are close to zero. If the attributable costs are considered and the calculation period covers several years, the approach is close to a calculation of a Customer Lifetime Value (CLV).

The exact procedure in quantifying the value perspectives must be examined case by case. A key prerequisite for $\mathrm{V} 2 \mathrm{~V}$ segmentation is that for an individual customer there is a classification in terms of the value-to-the-customer dimension as well as in terms of the value-of-the-customer dimension.

\section{The Value-to-Value-Approach (V2V) in the Business Practice}

The derived linking of both value perspectives in the context of a value-to-value segmentation in different markets is discussed with regard to the question, which strategic and operational aspects arise for the market development. Because of the diversity of market conditions, it is advisable to discuss B2B and B2C business models separately.

\subsection{Application in a Company in the Mobility Sector (B2C-relationship)}

The usually higher number of customers in B2C-markets constitutes an essential difference to B2B-markets. This leads to a relatively uncertain customer picture, if no transaction data is recorded at purchase. The following scenario from the mobility sector is no exception: With the aim of continuously optimizing the customer handling and touch points, the company has developed various segmentations (including product-oriented, demographic, customer value-oriented and psychographic approaches) in the past, but without sustained success. To develop the value-based marketing the CRM strategy was revised and completed with the implementation of a value-to-value customer segmentation. 
An essential challenge in the V2V-Approach is the determination of the value driver. If behavior- and preference information is available (usually in the existing CRM-systems), it can be directly used. This is the case in for example the telecommunication or banking sector (Bayer, 2010): They had to conduct an empirical study in the concrete project example, because the appropriate basis data about the customer value in the IT-system was not available. Concerning the methodical approach different instruments were evaluated, a. o. conjoint measurement, the stated-preference-method and a simple survey with consideration force (Kalt et. al., 2013). To specify the primary benefit by travel decisions a multistage trade-off-question was used. Also, by the determination of the customer value it is necessary to weigh between a maximal accuracy (with high resource employment) and a high focus on the essential drivers (exploratory economic acceptable). The challenge is to break the financial currents of the corporation down on the single customer or segment. This requires a close cooperation between various departments, a. o. strategy, marketing/sales, IT and controlling. The project focused on the derivation of the most important revenue and cost components, because depending on supply segment revenue calculations are very different. The cost assessment was focused on the customer attributable production costs. On this basis, a static customer value (contribution margin of the transport company) was calculated, that could be brought in a dynamic model by adding further information on the history of the customer relationship (contract duration of subscribers etc.). Finally, a 5-year period was used in the project to determine the individual customer lifetime value.

In a further step, the two value-perspectives (figure 5, left side) were merged. For this purpose, a unique customer (data) view was required. The determination of the number of segments to be processed must meet the basic requirements (adequate size, responsiveness). In the present case, the target dimensions are divided in triplicate, hence resulting in nine sub-segments. The relevance of the segments in terms of the dimensions of number of customers, revenues and costs differ significantly.

In addition to the $\mathrm{V} 2 \mathrm{~V}$ segmentation particular emphasis was placed on change management in the customer service. For this purpose it was necessary not only to describe the different segments, but also to transfer segment information into the CRM-database (Williams, 2014). While describing the status of the customer relationship, V2V segments were examined in terms of subscription percentage (figure 5, right side), as well as the degree of customer loyalty (number of subscriptions in the last 5 years), overall customer satisfaction and the repeat purchase intention regarding the subscription. From the perspective of customer development, opportunities were focused particularly on the question of how high the "share of wallet" is and whether there are chances to mobilize latent additional demand.

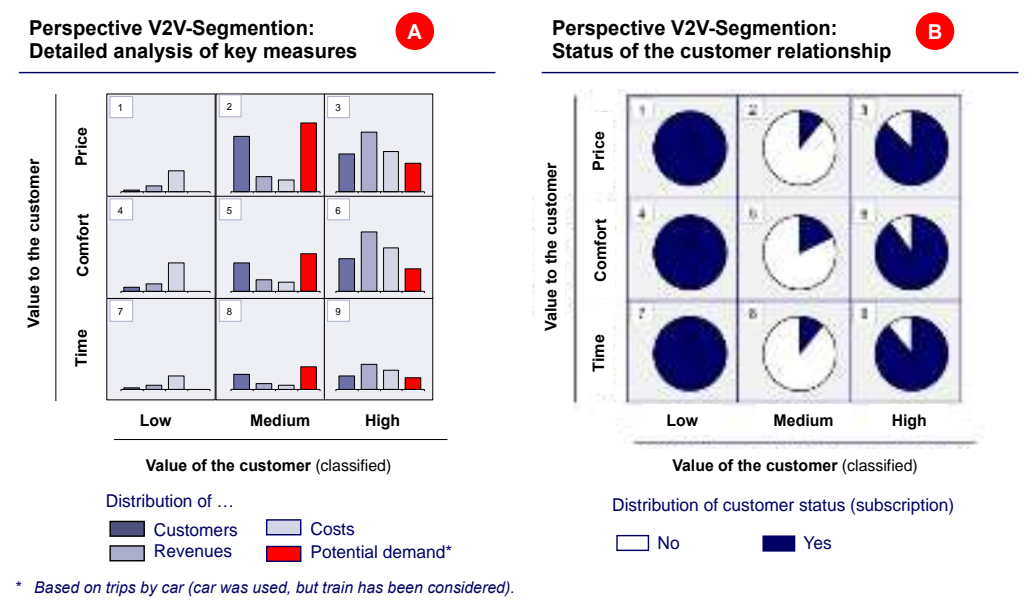

Figure 5. Example for a $V 2 V$-segmentation used in the mobility sector (B2C)

\subsection{Application in a Multimedia Company (B2B-Relationship)}

As part of the development of a strategy to expand international sales activities the status of the current customer relationships was analyzed in a first step for a multimedia company. The marketing activities were so far less oriented towards companies with sales activities in recent years, but rather on companies that were described as "interested parties" in the CRM database (contacts without sales). The term "interested" already implied that those contacts are regarded as very product affine (with high turnover potential). Based on an empirical study both groups (customers/prospects) were interviewed concerning several aspects (a. o. type of initial contact with the company, frequency of purchase, main reason for the purchase decision, future sales potential, customer satisfaction and willingness to recommend).

In figure 6 the results of the most important information using the V2V-segmentation are presented. From the strategic view it seems obvious that in particular segment 2 (high quality requirements combined with high contribution margin 
potential) is very important for the marketing activities and needs to be prioritized. In addition to that it is perceptible that almost half of the contacts in CRM-systems reflect companies, which are relatively price-sensitive. This is expressed in the evaluation of relevance of quality criteria proportional to the price importance, as well as in the assessment of the current price level.

Contrary to the assumption of the project participants that the initial contacts, which lead to sales and revenues, were induced by appearances in the Internet, in essence, the study results show a high relevance of recommendation (colleagues or from the private sphere) in the group with current customers. The analysis of the recommendation intention leads to a consistent picture: While the Net Promoter Score reached an intermediate level in the average of the companies surveyed, there are significant differences between clients (mean NPS 58\% points) and non-customers (mean NPS -8\%). This resulted in a paradigm shift concerning operational marketing activities. Since then, promotion of referral marketing has received a higher priority.

Concurrently, as a side effect, a row of weaknesses in the setup and in the use of the own CRM-data became evident. The implementation of the V2V-approach requires that the two value dimensions are also system technically illustrated. Therefore, a consistent customer view at the determination of "Value of the Customer" is required (central customer account, joining of all transactions and sales activities etc.). In regard to the driver of the buying decision ("Value to the Customer") a better care for the customer data and an expansion of expressed customer expectations (performance evaluation, customer satisfaction, evaluation of the price level etc.) is required.

\begin{tabular}{|l|}
\hline Methodology \\
\hline - Online-survey (contacts \\
from CRM data base) \\
- Value to the customer: \\
Weight of decision \\
factors was deter- \\
mined by a 100-point \\
constant sum scale \\
(quality items were \\
aggregated \\
- Value of the customer: \\
Focus on revenues \\
(3years) only; \\
assumption: marginal \\
costs=0.
\end{tabular}

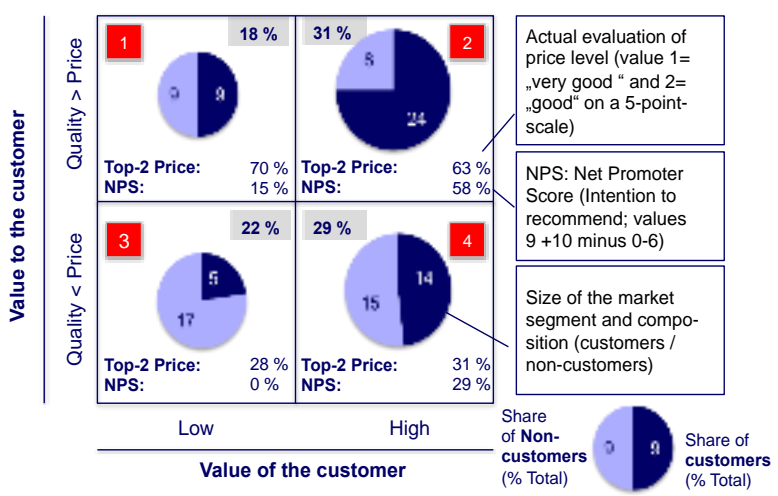

Figure 6. Example for a V2V-segmentation used in the multimedia sector (B2B)

Once, the segmentation of relevant customers is completed, it becomes evident, that the new market perspective offers additional views on the market and customer insights and thus supports the companies decision making process, be it in developing different price schemes, budget allocation and prioritizing customer support.

\section{Conclusion}

Basically, a customer relationship can be described and checked on different levels. According to the proposed three-layer model, the prospects business model, customer strategy and operative marketing can each be related to each other. Overall, it can be stated that the combination of "value to customer" and "value of the customer" analysis provides numerous starting points for understanding, managing and controlling the customer relationship state in the considered layers. Decisions on the allocation of resources to the different target groups can be improved by analyzing how the alignment is capitalized to the benefit requirements of the respective segments in terms of customer value.

The results of benefit segmentation allow, in a next step, to implement segment-specific marketing strategies and optimize compliance with the benefit requirements of valuable customers and therefore to increase customer satisfaction. The approach presented here takes both value perspectives into consideration - creating value for consumers ("value creation") and value creation for the supplier ("value appropriation"), allowing a focus on customer needs, and at the same time to analyse the economic impact of the efforts to improve customer orientation. The examples on both B2B and B2C markets illustrate a wide range of applications. Given the fact that many companies simultaneously work with different segmentations (each with an isolated point of view), makes it difficult or even impossible to create a single view of the customer (Williams, 2014). Here, the presented segmentation provides the chance to answer questions at different levels of the 3-layor-model with a customer-/finance-centric perspective.

A significant challenge of the approach is that the implementation requires a specific strategy, which has to take into account the characteristics in the specific company-customer-relationships. Another characteristic is the conjunction of the concept of the V2V-approach with the operational data management. Furthermore the integration of different data 
(sources) to ensure a success-oriented, IT-based customer value management is needed.

\section{References}

Bayer, J. (2010). Customer Segmentation in the Telecommunications Industry. Database Marketing \& Customer Strategy, 17(3/4), 247 - 256. http://dx.doi.org/10.1057/dbm.2010.21

Burgartz, T. (2008). Kennzahlengestütztes Kundenbeziehungs-Controlling. Ein konzeptioneller Ansatz zur entscheidungsorientierten Planung und Kontrolle von Kundenbeziehungen, Frankfurt a.M.

Cornelsen, J. (2000). Kundenwertanalysen im Beziehungsmarketing. Theoretische Grundlegung und Ergebnisse einer empirischen Studie im Automobilbereich, Nürnberg.

DER SPIEGEL (2013). Die Besessenen, 9, 82 - 85.

Gerth, N. (2001). Zur Bedeutung eines neuen Informationsmanagements für den CRM-Erfolg, Link, J. (ed.), Customer Relationship Management: Erfolgreiche Kundenbeziehungen durch integrierte Informationssysteme, 103-116. http://dx.doi.org/10.1007/978-3-642-56552-6_5

Gordon, H. I. (2013). Managing the new Customer Relationship: Strategies to Engage the Social Customer and Built Lasting Value, Wiley, Mississauga.

Hahn, C., Johnson, M. D., Herrmann, A., \& Huber, F. (2002). Capturing Customer Heterogeneity using a Finite Mixture PLS Approach, Schmalenbach Business Review, 54, 243-269.

Isaacson, W. (2011). Steve Jobs, Simon \& Schuster, New York.

Kalt, M., Bongaerts, R., \& Krämer, A. (2013). Value-to-Value-Segmentierung im praktischen Einsatz. Planung und Analyse, 40(6), 21-24.

Krämer, A., Bongaerts, R., \& Weber, A. (2003). Rabattsysteme und Bonusprogramme, Diller, H. / Herrmann, A. (eds.) Handbuch Preispolitik: Strategien - Planung - Organisation - Umsetzung, Wiesbaden, 551-574. http://dx.doi.org/10.1007/978-3-322-90512-3_27

Menon, A., Homburg, C., \& Beutin, N. (2005). Understanding Customer Value in Business-to Business Relationships, Journal of Business-to-Business Marketing, 12(2), 1-38. http://dx.doi.org/10.1300/J033v12n02_01

Murray, K B. (2013). The Retail Value Proposition - Crafting Unique Experiences at Compelling Prices, Toronto 2013.

Pan, X., \& Luo, X. (2006). Service Capabilities in Value Appropriation: A Conceptualization and Investigation of Internet Retailers, Working Paper, Indiana University, Bloomington.

PwC (2013). Innovation - Deutsche Wege zum Erfolg, no place of publication.

Reinartz, W. J., \& Krafft, M. (2001). Überprüfung des Zusammenhangs von Kundenbindungsdauer und Kundenertragswert, Zeitschrift für Betriebswirtschaft, 71(11), 1263-1281.

Rust, R. T., Lemon, K. N., \& Zeithaml, V. A. (2004). Return on Marketing: Using Customer Equity to Focus Marketing Strategy, Journal of Marketing, 68(1), 109 - 127. http://dx.doi.org/10.1509/jmkg.68.1.109.24030

SKP (2013). Simon, Kucher \& Partners: Discount is out. Download, 6.12.2013 http://www.simon-kucher.com/de/news/discount-ist-out.

Slotegraaf, R. J., Moorman, C., \& Inman, J. (2003).The Role of Firm Resources in Returns to Market Deployment, Journal of Marketing Research, 40(3), 295-309. http://dx.doi.org/10.1509/jmkr.40.3.295.19235

Subramanian, U., Raju, J. S., \& Zhang, Z. J. (2007). Customer Value-based Management: Competitive Implications. http://d1c25a6gwz7q5e.cloudfront.net/papers/1347.pdf

Venkatesan, R., \& Kumar, V. (2004). A Customer Lifetime Value Framework for Customer Selection and Resource Allocation Strategy, Journal of Marketing, 68(4), 106-125. http://dx.doi.org/10.1509/jmkg.68.4.106.42728

Williams, D. S. (2014). Connected CRM - Implementing a Data-Driven, Customer-Centric Business Strategy, Wiley, Hoboken.

Woodruff, R. B. (1997). Customer value: The next source for competitive advantage, Journal of the Academy of Marketing Science, 25(2), 139-153. http://dx.doi.org/10.1007/BF02894350

Zeithaml, V. A. (1988). Consumer perceptions of price, quality, and value: A means- end model and synthesis of evidence. Journal of Marketing, 52, 2-22. http://dx.doi.org/10.2307/1251446

\section{(cc) BY}

This work is licensed under a Creative Commons Attribution 3.0 License. 